\title{
Executive dysfunction in Parkinson's disease and timing deficits
}

\author{
Krystal L. Parker ${ }^{1}$, Dronacharya Lamichhane ${ }^{1}$, Marcelo S. Caetano ${ }^{2}$ and Nandakumar S. Narayanan ${ }^{1,3} *$ \\ 1 Department of Neurology, University of lowa Hospitals and Clinics, lowa City, IA, USA \\ ${ }^{2}$ Center for Mathematics, Computation and Cognition, Universidade Federal do ABC, Santo André, Brazil \\ ${ }^{3}$ Aging Mind and Brain Initiative, University of lowa Hospitals and Clinics, lowa City, IA, USA
}

\section{Edited by:}

Warren H. Meck, Duke University,

USA

Reviewed by:

Vinay V. Parikh, Temple University, USA

Daniel Claassen, Vanderbilt University,

USA

\section{${ }^{*}$ Correspondence:}

Nandakumar S. Narayanan,

Department of Neurology, University

of lowa Hospitals and Clinics, 200

Hawkins Drive, lowa City, IA 52243,

USA

e-mail: nandakumar-narayanan@

uiowa.edu
Patients with Parkinson's disease (PD) have deficits in perceptual timing, or the perception and estimation of time. PD patients can also have cognitive symptoms, including deficits in executive functions such as working memory, planning, and visuospatial attention. Here, we discuss how PD-related cognitive symptoms contribute to timing deficits. Timing is influenced by signaling of the neurotransmitter dopamine in the striatum. Timing also involves the frontal cortex, which is dysfunctional in PD. Frontal cortex impairments in PD may influence memory subsystems as well as decision processes during timing tasks. These data suggest that timing may be a type of executive function. As such, timing can be used to study the neural circuitry of cognitive symptoms of PD as they can be studied in animal models. Performance of timing tasks also maybe a useful clinical biomarker of frontal as well as striatal dysfunction in PD.

Keywords: temporal processing, executive function, cognitive impairment, Parkinson's disease, interval timing

\section{INTRODUCTION}

Parkinson's disease (PD) is a neurodegenerative disease where midbrain dopamine neurons inexorably die. Cardinal manifestations of PD include bradykinesia, rigidity, resting tremor, and postural instability. PD patients also have non-motor manifestations such as constipation, salivation, sleep disorders, mood disorders, and cognitive deficits (Chaudhuri and Schapira, 2009; Zesiewicz et al., 2010). Of these, executive dysfunction, one major domain of cognitive deficits in PD (Gotham et al., 1988; Cooper etal., 1991; Aarsland et al., 2010), is associated with considerable morbidity (Williams-Gray et al., 2007) and predicts future mortality (Santangelo et al., 2007; Forsaa et al., 2010).

Executive dysfunction affects roughly $30 \%$ of PD patients (Williams-Gray et al., 2009; Aarsland and Kurz, 2010). Deficits in executive tasks may define a disease trajectory, as cognitive symptoms are prognosticators of dementia onset (Mahieux et al., 1998; Levy et al., 2002a,b; Janvin et al., 2005). Such deficits can occur early in the disease (Foltynie et al., 2004; Aarsland et al., 2009) and involve impaired coordination of a range of cognitive processes required to achieve complex, goal-oriented, and novel cognitive operations (Elliott, 2003; Jurado and Rosselli, 2007). Executive processes include working memory, planning, inhibition, attention, and decreased speed of processing (Uc etal., 2005). These processes typically involve the frontal lobe (Fuster, 2008). These impairments are revealed using classic tests of executive function (Van Spaendonck et al., 1996) including verbal fluency, abstract reasoning, picture completion, Stroop performance (Aarsland etal., 2011), and performance on the Tower-of-London task (Foltynie et al., 2004). Executive functions can include inhibitory control (Stuss et al., 2005; Picton et al., 2006) which may be impaired in PD (Wylie et al., 2010; Mirabella et al., 2013). Other executive processes such as action selection can be impaired in PD and correlate with dysfunctional frontostriatal networks (Hughes et al., 2013). Here, we are particularly interested in working memory aspects of executive function, as these appear to be involved in timing (Gibbon et al., 1984) and impaired in PD patients (Malapani et al., 1998).

Importantly, PD-related executive dysfunction is not directly correlated with motor dysfunction (Van Spaendonck et al., 1996), although it has been linked with gait-disturbance (Wylie et al., 2012). Dopaminergic therapy does not reliably improve executive dysfunction in high-functioning (Pascual-Sedano et al., 2008) or moderate PD patients (Morrison et al., 2004) and potentially can have detrimental effects (Cools et al., 2001; Cools and D'Esposito, 2011).

In addition to deficits in executive dysfunction, patients with PD consistently have impaired timing (e.g., Artieda et al., 1992; O'Boyle et al., 1996; Malapani et al., 1998, 2002; Merchant et al., 2008; Jahanshahi et al., 2010; Jones et al., 2011). While some consider timing an executive function (Fuster, 2008), it is not universally considered as such (Elliott, 2003; Jurado and Rosselli, 2007). Executive functions classically involve goal-directed behavior such as planning, flexibility, problem solving, and attentional control (Baddeley and Hitch, 1974; Norman and Shallice, 1986; Lezak etal., 2004) rather than timing. In this review, we discuss evidence that (1) timing tasks involve executive processing in the frontal cortex, and (2) frontal dysfunction may contribute to timing deficits in PD patients.

\section{PERCEPTUAL TIMING}

Timing, i.e., the perception and estimation of time from seconds to minutes, is central in guiding a range of behaviors, from foraging and decision making to goal-directed behavior (Church, 1984). Perceptual timing at this scale can be measured using a variety of interval timing tasks. These tasks require subjects to make responses at precise times indicating their internal and subjective 
estimates of time. Interval timing is conserved across a wide range of species (Buhusi and Meck, 2005), and is distinct from other measures such as motor timing, implicit timing, ordinal timing, and rhythmic timing.

In order to understand perceptual timing, it is useful to construct a detailed model which accounts both for timing behavior and errors in timing. Understanding the neural basis of timing models can be used to illuminate the mechanism of brain diseases which produce timing errors. One prominent model of timing is the scalar timing theory or scalar expectancy theory, also referred to as the pacemaker-accumulator model of timing (Gibbon et al., 1984). This model assumes the existence of a pacemaker that emits pulses at a certain rate, an accumulator that stores these pulses, and a decision module that constantly compares the accumulated pulses with an example sampled from memory. According to this model (Figure 1), a discriminative signal triggers the accumulation of the pulses, which are regularly compared with a randomly sampled number of pulses from the reference memory related to that discriminative signal. When the comparison crosses a threshold, a response is triggered (Church, 1997, 2003). Each component in this model produces variability, and at least of one these must be scalar, producing linearly increasing variance (Gibbon et al., 1984). Of note, there are alternative interval timing theories that, arguing for a lack of biological validity, do not assume the existence of a pacemaker/accumulator-type internal clock (Buhusi and Oprisan, 2013; Laje and Buonomano, 2013); but see Simen et al. (2011) for a clock-like proposal of a neural model to estimate the passage of time). For instance, in a striatal beat-frequency model,

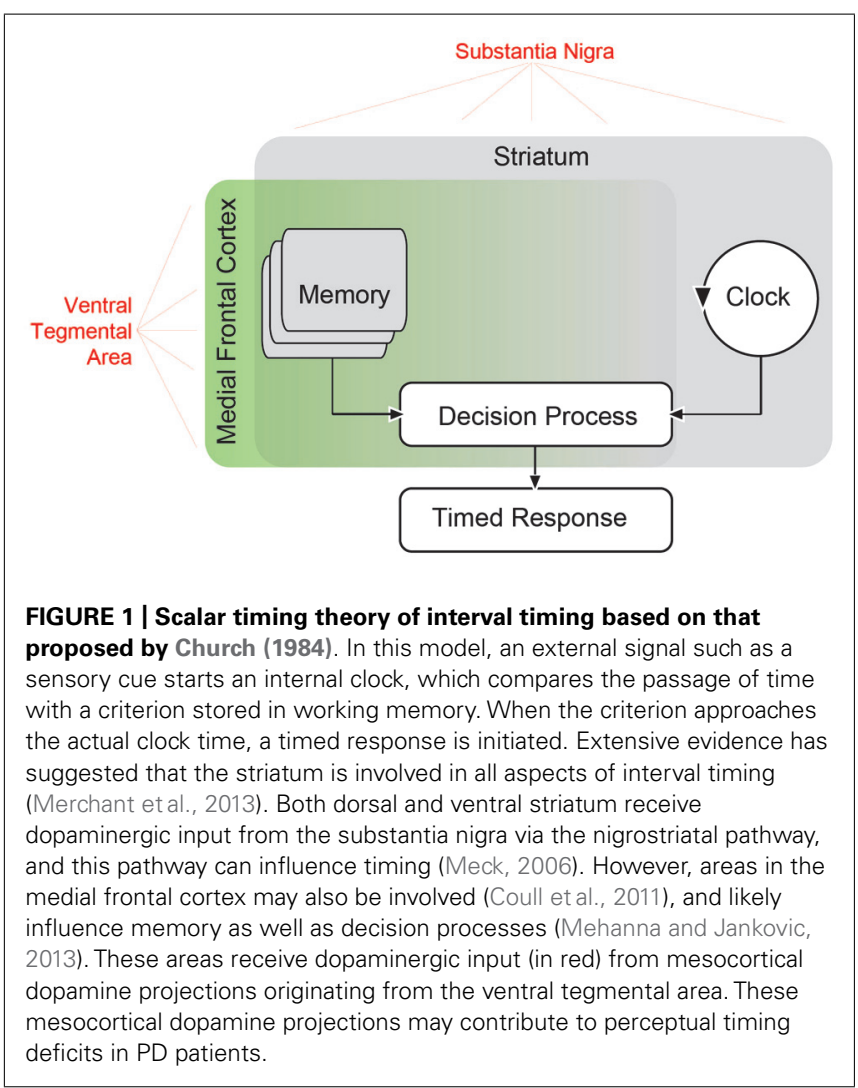

striatal medium-spiny neurons serve as timers by detecting and integrating oscillatory states overtime (Matell et al., 2003; Meck et al., 2008; Allman and Meck, 2012). Of these, the scalar timing theory remains the most influential.

A link between interval timing and executive function is that classic tasks loading executive function impair interval timing (Brown, 2006). For instance, remembering items interfered with subjects' ability to reproduce temporal epochs (Fortin and Rousseau, 1998). When children were asked to both estimate time and perform other executive processes, they were impaired (Rattat, 2010). These type impairments in dual-task experiments suggest that increased dual-task allocation to executive processing resulted in a tradeoff with perceptual timing performance (Brown et al., 2012). Interference seemed to be specifically constrained to the executive process of updating working memory buffers (Ogden et al., 2011). Taken together, these studies provide evidence that interval timing requires executive resources.

Perceptual timing has been reliably linked with dopamine signaling in the striatum (Buhusi and Meck, 2005; Jones and Jahanshahi, 2013). Interval timing can activate medial frontal regions (Hinton et al., 2004; Jahanshahi et al., 2010), including supplementary and pre-supplementary areas (Mita et al., 2009; Coull et al., 2011, 2012; Schneider and Ghose, 2012). Single neurons in medial prefrontal cortex are modulated by time (Niki and Watanabe, 1979; Meck et al., 2008; Genovesio et al., 2009; Narayanan and Laubach, 2009). Rodent studies using pharmacological and optogenetic methods have found that prefrontal D1 dopamine signaling is required for interval timing (Narayanan etal., 2012). A recent temporal discrimination task described that neuronal ensembles in rodent medial frontal cortex were modulated by the passage of time (Kim et al., 2013). These results suggest that interval timing and executive functions share similar neural networks.

Previous reviews have discussed the neuroanatomy of timing in great detail (Matell et al., 2003; Buhusi and Meck, 2005; Meck, 2006; Coull and Nobre, 2008; Coull et al., 2011). A central structure in interval timing is the striatum (Harrington et al., 1998; Jones and Jahanshahi, 2013), likely favoring dorsal striatum (Kurti and Matell, 2011). However, timing can involve diverse and distributed brain networks (Meck et al., 2008; Coull et al., 2011). In Figure 1, we have illustrated potential brain networks that underlie timing-related processes suggested by the scalar timing theory. For instance, it is clear that the striatum influences all aspects of perceptual timing, from clock functions to decision and memory mechanisms (Husárová et al., 2011, 2013; Coull etal., 2012; Merchant et al., 2013). While temporal memory is certainly likely to involve frontal networks (Shimamura et al., 1990), recent reviews noted that medial frontal and medial premotor networks were consistently activated by perceptual timing tasks (Coull and Nobre, 2008; Coull et al., 2011). These areas might provide "context" (Merchant et al., 2013) and serve as executive control processes. Many of the frontal areas consistently activated include motor, supplementary motor, and cingulate cortex, which we posit are involved in the response decisions. Systematic recording and disruption experiments from this network in animal models will clarify the role of frontal cortex in memory vs. decision functions during interval timing. 


\section{DOPAMINE AND INTERVAL TIMING}

The neurotransmitter dopamine is released from projections originating in the midbrain. Manipulations of dopaminergic signaling profoundly influence interval timing, leading to the hypothesis that dopamine influences internal pacemaker, or "clock," activity (Maricq and Church, 1983; Buhusi and Meck, 2005, 2009; Lake and Meck, 2013). For instance, amphetamine, which increases concentrations of dopamine at the synaptic cleft (Maricq and Church, 1983; Zetterström et al., 1983) advances the start of responding during interval timing (Taylor et al., 2007), whereas antagonists of D2 type dopamine receptors typically slow timing (Drew et al., 2003; Lake and Meck, 2013). Animal work has indicated that manipulations of both nigrostriatal (Drew et al., 2003, 2007; Meck, 2006) and mesocortical dopamine signaling originating from the ventral tegmental area (Narayanan et al., 2012) can also strongly influence interval timing.

In $\mathrm{PD}$, midbrain projection neurons containing dopamine die (Damier et al., 1999). PD patients are slow to initiate and execute movements (Evarts et al., 1981) and they also have impairments in interval timing. Early studies of PD patients off medication revealed a slowing of timing performance, which correlated with disease severity (Artieda et al., 1992; Pastor et al., 1992), and was consistent with bradykinesia observed with disease progression. Timing deficits were normalized by levodopa, and seem to be constrained to intervals on the scale of seconds (Koch et al., 2008). Notably, these patients had large variability in their estimates of time that was confirmed by a study in PD patients estimating two distinct intervals (Malapani et al., 1998). In this study, PD patients overestimated the short interval and underestimated the long interval; when they estimated the long interval only, they were slower. This effect, dubbed the "migration effect," has been reliably found in PD patients (Koch et al., 2005). Timing deficits can be rescued by dopaminergic therapy (Malapani et al., 1998), suggesting that beyond clock speed, mnemonic representation for time is impaired in PD and that dopamine influences memory as well as clock subsystems.

Parkinson's disease patients have timing impairments in related interval timing tasks. For instance, in a duration production and reproduction task with concurrent attentional loads, PD patients were more variable (Perbal et al., 2005). Both levodopa and stimulation of the subthalamic nucleus improved time reproduction (Torta et al., 2010). PD patients can also have deficits in processing temporal information at sub-second time scales (Harrington et al., 1998; Riesen and Schnider, 2001), but there is significant variability in timing at this scale (Merchant et al., 2008; Jones et al., 2011; Claassen et al., 2013). The consistency of PD timing deficits at seconds and inconsistency below milliseconds may be related to the memory and attentional load of longer time intervals (Koch et al., 2008). PD patients consistently tend to have slower, more variable timing over a scale of seconds, which implies that the loss of dopamine influences not only clock deficits in PD patients, but memory and decision processes as well (Mehanna and Jankovic, 2013; Figure 1).

Notably, in some studies levodopa normalizes timing (Malapani etal., 1998; Koch etal., 2008) but not other executive functions such as memory, reasoning, or flexible learning (Gotham etal., 1988; Cools etal., 2001; Pascual-Sedano etal.,
2008). Dopamine signaling may be complex with non-linearities (Cools and D'Esposito, 2011). Levodopa's effects may also be influenced by disease severity (Cools et al., 2001). Additionally, PD patients can be heterogeneous (Merchant et al., 2008; Aarsland et al., 2011) with respect to the disease.

Another possibility includes a role for non-dopaminergic signaling in PD-related cognitive dysfunction. Cortical and striatal areas are influenced by other broad neurotransmitter projection systems that are also impaired in PD, such as cholinergic projections originating from basal forebrain (Bigl et al., 1982). This area can be affected in PD patients (Arendt et al., 1983; Whitehouse et al., 1983; Fujita et al., 2006). Furthermore, clinical trials have demonstrated that cholinesterase inhibitor improves cognitive performance for PD patients with mild-moderate dementia (Emre et al., 2004; Poewe et al., 2006). Manipulations of cholinergic signaling (Meck and Church, 1987) and the basal forebrain (Olton et al., 1988) can strongly influence temporal memories. It is unclear if timing deficits are also improved in these patients.

Although PD also involves degeneration of many other brainstem projection nuclei (Scatton et al., 1983; Del Tredici et al., 2002; Jellinger, 2011) such as serotonin and norepinephrine (McCormick et al., 1985), the role of these systems in executive dysfunction and perceptual timing deficits is unclear. However, because levodopa does not reliably treat PD-related cognitive symptoms (Cools et al., 2001, 2002; Morrison et al., 2004; PascualSedano et al., 2008), other non-dopaminergic mechanisms may be important for understanding cognition in PD. Future studies involving detailed correlation of neuropathology with clinical phenotypes as well as specific manipulations of non-dopaminergic systems in animal models will clarify this issue.

\section{PD AND FRONTAL CORTEX}

Deficits in interval timing have been uniformly interpreted as arising from deficits in nigrostriatal dopamine depletion affecting basal ganglia circuitry (Buhusi and Meck, 2005; Coull et al., 2011). However, we note that PD can profoundly influence the function of frontal cortex. The source of cortical dopamine projections in the medial nigral and ventral tegmental midbrain (Williams and Goldman-Rakic, 1998) degenerate in PD (Javoy-Agid and Agid, 1980; Javoy-Agid et al., 1981; Dymecki et al., 1996). These studies suggest that ventral tegmental dopamine neurons degenerate to a lesser extent than the nearby substantia nigra, which primarily projects to the striatum. To date, the functional consequence of ventral tegmental degeneration is unclear (Jellinger, 1999), although there is debate about the involvement of ventral tegmental area in PD (Fearnley and Lees, 1991) likely because there is much overlap between these areas.

Midbrain dopamine neurons encode errors in temporal predictions of reward (Hollerman and Schultz, 1998; Fiorillo et al., 2008; Kobayashi and Schultz, 2008) and can precisely encode temporal information (Lapish et al., 2007). PD involves a dysfunction and loss of these neurons, which could lead to abnormalities in temporal processing in synaptic projection targets in the cortex and striatum. Without this input, these areas can be temporally desynchronized. Depletion of dopamine in healthy volunteers impairs timing (Coull et al., 2012), while amphetamine releases synaptic dopamine and speeds up timing (Taylor et al., 2007). 
Animal models which record from both dopamine and downstream neurons or dynamically manipulate dopamine neurons while recording in downstream areas will identify the precise role that dopamine release has on temporal encoding in cortex and striatum.

Metabolic imaging demonstrates that PD patients have alterations in prefrontal dopamine signaling (Dubois and Pillon, 1995, 1997) which has been confirmed by positron emission tomography (PET with 18F-DOPA; Rakshi et al., 1999; Kaasinen et al., 2001). These studies have reported that in early PD, prefrontal dopamine uptake has been reported to be increased, presumably due to compensatory mechanisms. Dopamine influences executive function via mesocortical projections originating from the ventral tegmental area (Arnsten and Li, 2005; Cools and D'Esposito, 2011). Prefrontal dopamine release measured by microdialysis is correlated with working memory performance (Phillips et al., 2004). Blocking prefrontal D1 receptors degrades the ability of prefrontal neurons to represent items in working memory (Williams and Goldman-Rakic, 1995; Goldman-Rakic et al., 2004; Wang et al., 2004). In rodent models, prefrontal D1 receptors are associated specifically with interval timing (Narayanan et al., 2012) as well as memory (Seamans et al., 1998; Floresco and Phillips, 2001). In addition, prefrontal dopamine signaling has been linked with a variety of cognitive behaviors, such as reasoning (Takahashi et al., 2012), attentional set-shifting (Floresco et al., 2006), reversal learning (Kehagia et al., 2010), impulsivity (Loos et al., 2010), and decision-making (Floresco, 2013). Dopamine release in prefrontal cortex can modulate network state (Seamans and Yang, 2004). These studies suggest that abnormalities in prefrontal dopamine signaling in PD could impair executive processing (Miller and Cohen, 2001).

Cognitive symptoms of PD appear can be linked with dysfunction in prefrontal networks. Deactivation in medial prefrontal cortex is associated with cognitive dysfunction in PD in metabolic imaging studies (Huang et al., 2007). Brain imaging studies in PD patients have found aberrant prefrontal networks. For example, controls activated medial frontal networks more reliably than PD patients during a task of random numbers generation (Dirnberger et al., 2005). Levodopa restored prefrontal blood flow as measured by PET during performance on a Tower-of-London task (Cools et al., 2002). Decreased performance on attentional set-shifting by PD patients is correlated with less prefrontal metabolic activity (Sawada et al., 2012). This line of research suggests that there is executive dysfunction in PD that may involve the frontal cortex during timing tasks.

Several studies directly engage this question (Table 1). In a study of paced-finger tapping, less medial premotor as well as sensorimotor and cerebellar activity was observed in PD patients relative to controls (Elsinger et al., 2003). While on and off levodopa, Harrington et al. (2011) asked PD patients to perform a perceptual timing task, comparing two intervals of time while collecting functional magnetic resonance images (fMRI). This study found temporal impairments throughout frontostriatal and cerebellar networks, and found abnormal activations in medial frontal and parietal areas, which are typically associated with executive processes such as working memory. Activity in this network was abnormal while PD patients encoded time and absent during the decision phase; furthermore, in medial frontal areas such as the cingulate cortex, different temporal profiles were observed in concert with temporal alterations in the striatum. A study modeling effective connectivity found that in controls, medial supplementary motor areas had excitatory coupling with subcortical areas, while PD patients did not (Husárová et al., 2013). Some studies find no changes in this circuit in PD patients during timing tasks (Cerasa et al., 2006; Praamstra and Pope, 2007); of note, this may be related to both disease and pathological heterogeneities in PD patients (Merchant et al., 2008; Aarsland et al., 2011). Nonetheless, PD patients with timing-related dysfunction have abnormalities in medial frontal areas (including supplementary motor areas) in addition to the basal ganglia and cerebellum.

These data are supported with neurophysiological studies from animal models. For instance, in a temporal judgment task, primate prefrontal neurons predominantly encoded temporal duration (Genovesio et al., 2009). These same neurons were robustly modulated during the response window when a judgment was made. Similar patterns have also been observed in rodent frontal cortex (Narayanan and Laubach, 2006, 2009; Kim et al., 2013), and suggest that medial frontal cortex plays an essential role in encoding and judging temporal information.

Notably, the frontal cortex and striatum function together as a circuit (Alexander et al., 1986), and several of the preceding studies involved PD-related abnormalities in the striatum as well as the frontal cortex (Elsinger et al., 2003; Harrington et al., 2011; Husárová et al., 2011) which could be modulated by dopamine (Jahanshahi etal., 2010). Effective connectivity analyses suggest that striatal and cortical areas work together to guide behavior during timing tasks (Husárová et al., 2013). However, investigating the precise mechanistic relationships among areas in the frontal cortex and striatum would require recording from both areas simultaneously or inactivating one area and examining neural activity in the other. Intraoperative recording during deep-brain stimulation surgery (Sheth et al., 2012) or recording from animal models (Narayanan and Laubach, 2006) could investigate this question in detail.

Several investigators have suggested that timing deficits in PD may involve cognitive processing well beyond motor timing such as memory (Malapani et al., 1998; Koch et al., 2008). Imaging studies have captured deficits in control processing originating from medial regions of the frontal cortex (Jahanshahi et al., 2010; Harrington et al., 2011). These data suggest that interval timing and executive functions share resources in the medial frontal cortex, and that dysfunctional timing in Parkinson's patients may involve frontal as well striatal circuitry.

There are two clear implications supporting this idea. First, interval timing may be a useful clinical tool to assess the integrity of the frontostriatal system (Wild-Wall et al., 2008). One could imagine a specific interval timing paradigm to assess perceptual timing with a range of intervals spanning milliseconds to several seconds targeted at assaying both motor timing and higher order processing. As such, this task could provide early detection of timing deficits. Such a test would be simple, readily added to a neuropsychological battery or even administered remotely (Sternberg et al., 2013) to assist in diagnosis of disease, screen for 
Table 1 | Studies that examine the neuroanatomical basis of timing deficits and PD.

\begin{tabular}{|c|c|c|c|}
\hline Study & Task & Subjects & Hypoactive areas in PD patients \\
\hline Harrington etal. (2011) & Time perception task & Controls PD patients on/and off & $\begin{array}{l}\text { Middle frontal cortex/parietal cortex - temporal encoding } \\
\text { striatal dysfunction - time keeping }\end{array}$ \\
\hline Jahanshahi et al. (2010) & Finger tapping & Controls PD patients on/and off & $\begin{array}{l}\text { No activation in medial frontal cortex, cingulate, hippocampus, } \\
\text { accumbens during timing }\end{array}$ \\
\hline Elsinger et al. (2003) & Finger tapping & Controls PD patients on/and off & $\begin{array}{l}\text { Decreased activation in medial premotor cortex, sensorimotor } \\
\text { cortex, and cerebellum }\end{array}$ \\
\hline Cerasa et al. (2006) & $\begin{array}{l}\text { Internally timed } \\
\text { movements }\end{array}$ & Controls PD patients on/and off & $\begin{array}{l}\text { Similar supplementary motor and subcortical areas in PD } \\
\text { patients OFFand controls }\end{array}$ \\
\hline Praamstra and Pope (2007) & $\begin{array}{l}\text { Timed choice reaction } \\
\text { time task }\end{array}$ & Controls vs. PD patients & Abnormal beta/alpha activity related to temporal preparation \\
\hline Husárová etal. (2013) & Motor timing task & Controls vs. PD patients off & $\begin{array}{l}\text { Similar area: supplementary motor, basal ganglia, cerebellum, } \\
\text { putamen. PD patients had an inhibitory SMA-Cb connection. }\end{array}$ \\
\hline Husárová etal. (2011) & Motor timing & Contols vs. PD patients off & $\begin{array}{l}\text { Did not include cortical cuts; less basal ganglia/cerebellum in } \\
\text { PD patients. }\end{array}$ \\
\hline
\end{tabular}

executive dysfunction, track disease progression, and/or response to therapy.

Secondly, perceptual timing tasks can be readily trained in animals (Coull et al., 2011) such as rodents (Balci et al., 2008) or pigeons (Ludvig et al., 2011). This enables detailed, mechanistic investigation of neural circuits underlying the temporal organization of motivated behavior with tools such as transgenic mice (Drew et al., 2007), optogenetics (Narayanan et al., 2012), and neuronal ensemble recording (Matell etal., 2003; Kim et al., 2013). These circuits can be investigated in detail to understand how frontostriatal circuits are involved in perceptual timing.

In summary, we have suggested that perceptual timing is a type of executive function. Considering it as such implies that testing perceptual timing is a useful way of testing cognitive function in PD patients. Detailed mechanistic understanding of the neural circuits involved in perceptual timing in PD could lead to a greater understanding of the cognitive symptoms of PD and to targeted therapies for this difficult clinical problem.

\section{ACKNOWLEDGMENT}

This work was supported by an NINDS K08 to Nandakumar S. Narayanan.

\section{REFERENCES}

Aarsland, D., Brønnick, K., and Fladby, T. (2011). Mild cognitive impairment in Parkinson's disease. Curr. Neurol. Neurosci. Rep. 11, 371-378. doi: 10.1007/s11910-011-0203-1

Aarsland, D., Brønnick, K., Larsen, J. P., Tysnes, O. B., and Alves, G. (2009). Cognitive impairment in incident, untreated Parkinson disease: the Norwegian ParkWest study. Neurology 72, 1121-1126. doi: 10.1212/01.wnl.0000338632.00552.cb

Aarsland, D., Bronnick, K., Williams-Gray, C., Weintraub, D., Marder, K., Kulisevsky, J., et al. (2010). Mild cognitive impairment in Parkinson disease: a multicenter pooled analysis. Neurology $75,1062-1069$. doi: 10.1212/WNL.0b013e3181f39d0e

Aarsland, D., and Kurz, M. W. (2010). The epidemiology of dementia associated with Parkinson's disease. Brain Pathol. 20, 633-639. doi: 10.1111/j.17503639.2009.00369.x
Alexander, G. E., DeLong, M. R., and Strick, P. L. (1986). Parallel organization of functionally segregated circuits linking basal ganglia and cortex. Annu. Rev. Neurosci. 9, 357-381. doi: 10.1146/annurev.ne.09.030186.002041

Allman, M. J., and Meck, W. H. (2012). Pathophysiological distortions in time perception and timed performance. Brain 135, 656-677. doi: 10.1093/brain/ awr 210

Arendt, T., Bigl, V., Arendt, A., and Tennstedt, A. (1983). Loss of neurons in the nucleus basalis of Meynert in Alzheimer's disease, paralysis agitans and Korsakoff's disease. Acta Neuropathol. 61, 101-108. doi: 10.1007/BF00697388

Arnsten, A. F. T., and Li, B-M. (2005). Neurobiology of executive functions: catecholamine influences on prefrontal cortical functions. Biol. Psychiatry 57, 1377-1384. doi: 10.1016/j.biopsych.2004.08.019

Artieda, J., Pastor, M. A., Lacruz, F., and Obeso, J. A. (1992). Temporal discrimination is abnormal in Parkinson's disease. Brain 115, 199-210. doi: 10.1093/brain/115.1.199

Baddeley, A., and Hitch, G. (1974). Working Memory. New York: Academic Press.

Balci, F., Papachristos, E. B., Gallistel, C. R., Brunner, D., Gibson, J., and Shumyatsky, G. P. (2008). Interval timing in genetically modified mice: a simple paradigm. Genes Brain Behav. 7, 373-384. doi: 10.1111/j.1601-183X.2007.00348.x

Bigl, V., Woolf, N. J., and Butcher, L. L. (1982). Cholinergic projections from the basal forebrain to frontal, parietal, temporal, occipital, and cingulate cortices: a combined fluorescent tracer and acetylcholinesterase analysis. Brain Res. Bull. 8, 727-749. doi: 10.1016/0361-9230(82)90101-0

Brown, S. W. (2006). Timing and executive function: bidirectional interference between concurrent temporal production and randomization tasks. Mem. Cogn. 34, 1464-1471. doi: 10.3758/BF03195911

Brown, S. W., Collier, S. A., and Night, J. C. (2012). Timing and executive resources: dual-task interference patterns between temporal production and shifting, updating, and inhibition tasks. J. Exp. Psychol. Hum. Percept. Perform. 39, 947-963. doi: $10.1037 / \mathrm{a} 0030484$

Buhusi, C. V., and Meck, W. H. (2005). What makes us tick? Functional and neural mechanisms of interval timing. Nat. Rev. Neurosci 6, 755-765. doi: $10.1038 / \mathrm{nrn} 1764$

Buhusi, C. V., and Meck, W. H. (2009). Relativity theory and time perception: single or multiple clocks? PLoS ONE 4:e6268. doi: 10.1371/journal.pone.0006268

Buhusi, C. V., and Oprisan, S. A. (2013). Time-scale invariance as an emergent property in a perceptron with realistic, noisy neurons. Behav. Processes 95, 60-70. doi: 10.1016/j.beproc.2013.02.015

Cerasa, A., Hagberg, G. E., Peppe, A., Bianciardi, M., Gioia, M. C., Costa, A., et al. (2006). Functional changes in the activity of cerebellum and frontostriatal regions during externally and internally timed movement in Parkinson's disease. Brain Res. Bull. 71, 259-269. doi: 10.1016/j.brainresbull.2006.09.014 
Chaudhuri, K. R., and Schapira, A. H. V. (2009). Non-motor symptoms of Parkinson's disease: dopaminergic pathophysiology and treatment. Lancet Neurol. 8, 464-474. doi: 10.1016/S1474-4422(09)70068-7

Church, R. (2003). "A concise introduction to scalar timing theory," in Functional and Neural Mechanisms of Interval Timing, ed. W. Meck (New York: CRC Press), $3-22$.

Church, R. M. (1984). Properties of the internal clock. Ann. N.Y. Acad. Sci. 423, 566-582. doi: 10.1111/j.1749-6632.1984.tb23459.x

Church, R. M. (1997). Quantitative models of animal learning and cognition. J. Exp. Psychol. Anim. Behav. Process. 23, 379-389. doi: 10.1037/0097-7403.23.4.379

Claassen, D. O., Jones, C. R. G., Yu, M., Dirnberger, G., Malone, T., Parkinson, M., et al. (2013). Deciphering the impact of cerebellar and basal ganglia dysfunction in accuracy and variability of motor timing. Neuropsychologia 51, 267-274. doi: 10.1016/j.neuropsychologia.2012.09.018

Cools, R., Barker, R. A., Sahakian, B. J., and Robbins, T. W. (2001). Enhanced or impaired cognitive function in Parkinson's disease as a function of dopaminergic medication and task demands. Cereb. Cortex 11, 1136-1143. doi: $10.1093 /$ cercor/11.12.1136

Cools, R., and D'Esposito, M. (2011). Inverted-U-shaped dopamine actions on human working memory and cognitive control. Biol. Psychiatry 69, e113-e125. doi: 10.1016/j.biopsych.2011.03.028

Cools, R., Stefanova, E., Barker, R. A., Robbins, T. W., and Owen, A. M. (2002). Dopaminergic modulation of high-level cognition in Parkinson's disease: the role of the prefrontal cortex revealed by PET. Brain 125, 584-594. doi: 10.1093/brain/awf052

Cooper, J. A., Sagar, H. J., Jordan, N., Harvey, N. S., and Sullivan, E. V. (1991). Cognitive impairment in early, untreated Parkinson's disease and its relationship to motor disability. Brain 114(Pt 5), 2095-2122. doi: 10.1093/brain/114.5.2095

Coull, J., and Nobre, A. (2008). Dissociating explicit timing from temporal expectation with fMRI. Curr. Opin. Neurobiol. 18, 137-144. doi: 10.1016/j.conb.2008.07.011

Coull, J. T., Cheng, R.-K., and Meck, W. H. (2011). Neuroanatomical and neurochemical substrates of timing. Neuropsychopharmacology 36, 3-25. doi: 10.1038/npp. 2010.113

Coull, J. T., Hwang, H. J., Leyton, M., and Dagher, A. (2012). Dopamine precursor depletion impairs timing in healthy volunteers by attenuating activity in putamen and supplementary motor area. J. Neurosci. 32, 16704-16715. doi: 10.1523/JNEUROSCI.1258-12.2012

Damier, P., Hirsch, E. C., Agid, Y., and Graybiel, A. M. (1999). The substantia nigra of the human brain II. Patterns of loss of dopamine-containing neurons in Parkinson's disease. Brain 122, 1437-1448. doi: 10.1093/brain/122.8.1437

Del Tredici, K., Rüb, U., De Vos, R. A. I., Bohl, J. R. E., and Braak, H. (2002). Where does Parkinson disease pathology begin in the brain? J. Neuropathol. Exp. Neurol. 61, 413-426.

Dirnberger, G., Frith, C. D., and Jahanshahi, M. (2005). Executive dysfunction in Parkinson's disease is associated with altered pallidal-frontal processing. Neuroimage 25, 588-599. doi: 10.1016/j.neuroimage.2004. 11.023

Drew, M. R., Fairhurst, S., Malapani, C., Horvitz, J. C., and Balsam, P. D. (2003). Effects of dopamine antagonists on the timing of two intervals. Pharmacol. Biochem. Behav. 75, 9-15. doi: 10.1016/S0091-3057(03)00036-4

Drew, M. R., Simpson, E. H., Kellendonk, C., Herzberg, W. G., Lipatova, O., Fairhurst, S., et al. (2007). Transient overexpression of striatal D2 receptors impairs operant motivation and interval timing. J. Neurosci. 27, 7731-7739. doi: 10.1523/JNEUROSCI.1736-07.2007

Dubois, B., and Pillon, B. (1995). Do cognitive changes of Parkinson's disease result from dopamine depletion? J. Neural Transm. Suppl. 45, 27-34.

Dubois, B., and Pillon, B. (1997). Cognitive deficits in Parkinson's disease. J. Neurol. 244, 2-8. doi: 10.1007/PL00007725

Dymecki, J., Lechowicz, W., Bertrand, E., and Szpak, G. M. (1996). Changes in dopaminergic neurons of the mesocorticolimbic system in Parkinson's disease. Folia Neuropathol. 34, 102-106.

Elliott, R. (2003). Executive functions and their disorders. Br. Med. Bull. 65, 49-59. doi: 10.1093/bmb/65.1.49

Elsinger, C. L., Rao, S. M., Zimbelman, J. L., Reynolds, N. C., Blindauer, K. A., and Hoffmann, R. G. (2003). Neural basis for impaired time reproduction in Parkinson's disease: an fMRI study. J. Int. Neuropsychol. Soc. 9, 1088-1098. doi: $10.1017 /$ S1355617703970123
Emre, M., Aarsland, D., Albanese, A., Byrne, E. J., Deuschl, G., De Deyn, P. P., et al. (2004). Rivastigmine for dementia associated with Parkinson's disease. N. Engl. J. Med. 351, 2509-2518. doi: 10.1056/NEJMoa041470

Evarts, E. V., Teräväinen, H., and Calne, D. B. (1981). Reaction time in Parkinson's disease. Brain 104, 167-186. doi: 10.1093/brain/104.1.167

Fearnley, J. M., and Lees, A. J. (1991). Ageing and Parkinson's disease: substantia nigra regional selectivity. Brain 114, 2283-2301. doi: 10.1093/brain/114.5.2283

Fiorillo, C. D., Newsome, W. T., and Schultz, W. (2008). The temporal precision of reward prediction in dopamine neurons. Nat. Neurosci. 11, 966-973. doi: $10.1038 / \mathrm{nn} .2159$

Floresco, S. B. (2013). Prefrontal dopamine and behavioral flexibility: shifting from an "inverted-U" toward a family of functions. Front. Neurosci. 7:62. doi: $10.3389 /$ fnins.2013.00062

Floresco, S. B., Magyar, O., Ghods-Sharifi, S., Vexelman, C., and Tse, M. T. L. (2006). Multiple dopamine receptor subtypes in the medial prefrontal cortex of the rat regulate set-shifting. Neuropsychopharmacology 31, 297-309. doi: 10.1038/sj.npp.1300825

Floresco, S. B., and Phillips, A. G. (2001). Delay-dependent modulation of memory retrieval by infusion of a dopamine D1 agonist into the rat medial prefrontal cortex. Behav. Neurosci. 115, 934-939. doi: 10.1037/0735-7044.115.4.934

Foltynie, T., Brayne, C. E. G., Robbins, T. W., and Barker, R. A. (2004). The cognitive ability of an incident cohort of Parkinson's patients in the UK. The CamPaIGN study. Brain 127, 550-560. doi: 10.1093/brain/awh067

Forsaa, E. B., Larsen, J. P., Wentzel-Larsen, T., and Alves, G. (2010). What predicts mortality in Parkinson disease? A prospective population-based long-term study. Neurology 75, 1270-1276. doi: 10.1212/WNL.0b013e3181f61311

Fortin, C., and Rousseau, R. (1998). Interference from short-term memory processing on encoding and reproducing brief durations. Psychol. Res. 61, 269-276. doi: $10.1007 / \mathrm{s} 004260050031$

Fujita, M., Ichise, M., Zoghbi, S. S., Liow, J.-S., Ghose, S., Vines, D. C., et al. (2006). Widespread decrease of nicotinic acetylcholine receptors in Parkinson's disease. Ann. Neurol. 59, 174-177. doi: 10.1002/ana.20688

Fuster, J. (2008). The Prefrontal Cortex, 4th Edn. New York, NY: Academic Press.

Genovesio, A., Tsujimoto, S., and Wise, S. P. (2009). Feature- and orderbased timing representations in the frontal cortex. Neuron 63, 254-266. doi: 10.1016/j.neuron.2009.06.018

Gibbon, J., Church, R. M., and Meck, W. H. (1984). Scalar timing in memory. Ann. N.Y. Acad. Sci. 423, 52-77. doi: 10.1111/j.1749-6632.1984.tb23417.x

Goldman-Rakic, P. S., Castner, S. A., Svensson, T. H., Siever, L. J., and Williams, G. V. (2004). Targeting the dopamine D1 receptor in schizophrenia: insights for cognitive dysfunction. Psychopharmacology (Berl.) 174, 3-16. doi: 10.1007/s00213-004-1793-y

Gotham, A. M., Brown, R. G., and Marsden, C. D. (1988). "Frontal" cognitive function in patients with Parkinson's disease "on" and "off” levodopa. Brain 111(Pt 2), 299-321. doi: 10.1093/brain/111.2.299

Harrington, D. L., Castillo, G. N., Greenberg, P. A., Song, D. D., Lessig, S., Lee, R. R., et al. (2011). Neurobehavioral mechanisms of temporal processing deficits in Parkinson's disease. PLoS ONE 6:e17461. doi: 10.1371/journal.pone.0017461

Harrington, D. L., Haaland, K. Y., and Hermanowicz, N. (1998). Temporal processing in the basal ganglia. Neuropsychology 12, 3-12. doi: 10.1037/0894-4105.12.1.3 Hinton, S. C., Harrington, D. L., Binder, J. R., Durgerian, S., and Rao, S. M. (2004). Neural systems supporting timing and chronometric counting: an FMRI study. Brain Res. Cogn. Brain Res. 21, 183-192. doi: 10.1016/j.cogbrainres.2004.04.009

Hollerman, J. R., and Schultz, W. (1998). Dopamine neurons report an error in the temporal prediction of reward during learning. Nat. Neurosci. 1, 304-309. doi: $10.1038 / 1124$

Huang, C., Mattis, P., Tang, C., Perrine, K., Carbon, M., and Eidelberg, D. (2007). Metabolic brain networks associated with cognitive function in Parkinson's disease. Neuroimage 34, 714-723. doi: 10.1016/j.neuroimage.2006.09.003

Hughes, L. E., Altena, E., Barker, R. A., and Rowe, J. B. (2013). Perseveration and choice in Parkinson's disease: the impact of progressive frontostriatal dysfunction on action decisions. Cereb. Cortex 23, 1572-1581. doi: 10.1093/cercor/bhs144

Husárová, I., Lungu, O. V., Mareček, R., Mikl, M., Gescheidt, T., Krupa, P., et al. (2011). Functional imaging of the cerebellum and basal ganglia during predictive motor timing in early Parkinson's disease. J. Neuroimaging doi: 10.1111/j.15526569.2011.00663.x [Epub ahead of print].

Husárová, I., Mikl, M., Lungu, O. V., Mareček, R., Vaníček, J., and Bareš, M. (2013). Similar circuits but different connectivity patterns between the cerebellum, basal 
ganglia, and supplementary motor area in early Parkinson's disease patients and controls during predictive motor timing. J. Neuroimaging doi: 10.1111/jon.12030 [Epub ahead of print].

Jahanshahi, M., Jones, C. R. G., Zijlmans, J., Katzenschlager, R., Lee, L., Quinn, N., et al. (2010). Dopaminergic modulation of striato-frontal connectivity during motor timing in Parkinson's disease. Brain 133, 727-745. doi: 10.1093/brain/awq012

Janvin, C. C., Aarsland, D., and Larsen, J. P. (2005). Cognitive predictors of dementia in Parkinson's disease: a community-based, 4-year longitudinal study. J. Geriatr. Psychiatry Neurol. 18, 149-154. doi: 10.1177/0891988705277540

Javoy-Agid, F., and Agid, Y. (1980). Is the mesocortical dopaminergic system involved in Parkinson disease? Neurology 30, 1326-1330. doi: 10.1212/WNL.30.12.1326

Javoy-Agid, F., Ploska, A., and Agid, Y. (1981). Microtopography of tyrosine hydroxylase, glutamic acid decarboxylase, and choline acetyltransferase in the substantia nigra and ventral tegmental area of control and Parkinsonian brains. J. Neurochem. 37, 1218-1227. doi: 10.1111/j.1471-4159.1981.tb04672.x

Jellinger, K. A. (1999). Post mortem studies in Parkinson's disease: is it possible to detect brain areas for specific symptoms? J. Neural Transm. Suppl. 56, 1-29. doi: 10.1007/978-3-7091-6360-3_1

Jellinger, K. A. (2011). Synuclein deposition and non-motor symptoms in Parkinson disease. J. Neurol. Sci. 310, 107-111. doi: 10.1016/j.jns.2011.04.012

Jones, C. R., and Jahanshahi, M. (2013). Contributions of the basal ganglia to temporal processing: evidence from Parkinson's disease. Timing Time Percept. 1 , $1-41$.

Jones, C. R. G., Claassen, D. O., Yu, M., Spies, J. R., Malone, T., Dirnberger, G. et al. (2011). Modeling accuracy and variability of motor timing in treated and untreated Parkinson's disease and healthy controls. Front. Integr. Neurosci. 5:81. doi: $10.3389 /$ fnint.2011.00081

Jurado, M. B., and Rosselli, M. (2007). The elusive nature of executive functions: a review of our current understanding. Neuropsychol. Rev. 17, 213-233. doi $10.1007 /$ s11065-007-9040-z

Kaasinen, V., Nurmi, E., Brück, A., Eskola, O., Bergman, J., Solin, O., et al (2001). Increased frontal [(18)F]fluorodopa uptake in early Parkinson's disease: sex differences in the prefrontal cortex. Brain 124, 1125-1130. doi: 10.1093/brain/124.6.1125

Kehagia, A. A., Murray, G. K., and Robbins, T. W. (2010). Learning and cognitive flexibility: frontostriatal function and monoaminergic modulation. Curr. Opin. Neurobiol. 20, 199-204. doi: 10.1016/j.conb.2010.01.007

Kim, J., Ghim, J.-W., Lee, J. H., and Jung, M. W. (2013). Neural correlates of interval timing in rodent prefrontal cortex. J. Neurosci. 33, 13834-13847. doi: 10.1523/JNEUROSCI.1443-13.2013

Kobayashi, S., and Schultz, W. (2008). Influence of reward delays on responses of dopamine neurons. J. Neurosci. 28, 7837-7846. doi: 10.1523/JNEUROSCI.160008.2008

Koch, G., Brusa, L., Oliveri, M., Stanzione, P., and Caltagirone, C. (2005). Memory for time intervals is impaired in left hemi-Parkinson patients. Neuropsychologia 43, 1163-1167. doi: 10.1016/j.neuropsychologia.2004.11.017

Koch, G., Costa, A., Brusa, L., Peppe, A., Gatto, I., Torriero, S., et al. (2008). Impaired reproduction of second but not millisecond time intervals in Parkinson's disease. Neuropsychologia 46, 1305-1313. doi: 10.1016/j.neuropsychologia.2007.12. 005

Kurti, A. N., and Matell, M. S. (2011). Nucleus accumbens dopamine modulates response rate but not response timing in an interval timing task. Behav. Neurosci. 125, 215-225. doi: 10.1037/a0022892

Laje, R., and Buonomano, D. V. (2013). Robust timing and motor patterns by taming chaos in recurrent neural networks. Nat. Neurosci. 16, 925-933. doi: 10.1038/nn.3405

Lake, J. I., and Meck, W. H. (2013). Differential effects of amphetamine and haloperidol on temporal reproduction: dopaminergic regulation of attention and clock speed. Neuropsychologia 51, 284-292. doi: 10.1016/j.neuropsychologia.2012.09.014

Lapish, C. C., Kroener, S., Durstewitz, D., Lavin, A., and Seamans, J. K. (2007). The ability of the mesocortical dopamine system to operate in distinct temporal modes. Psychopharmacology (Berl.) 191, 609-625. doi: 10.1007/s00213-0060527-8

Levy, G., Jacobs, D. M., Tang, M.-X., Côté, L. J., Louis, E. D., Alfaro, B., et al. (2002a). Memory and executive function impairment predict dementia in Parkinson's disease. Mov. Disord. 17, 1221-1226. doi: 10.1002/mds. 10280
Levy, G., Tang, M. -X., Louis, E. D., Côté, L. J., Alfaro, B., Mejia, H., et al. (2002b). The association of incident dementia with mortality in PD. Neurology 59, 1708-1713. doi: 10.1212/01.WNL.0000036610.36834.E0

Lezak, M. D., Howieson, D. B., and Loring, D. W. (2004). Neuropsychological Assessment, 4th Edn. New York, NY: Oxford University Press.

Loos, M., Pattij, T., Janssen, M. C. W., Counotte, D. S., Schoffelmeer, A. N. M., Smit, A. B., etal. (2010). Dopamine receptor D1/D5 gene expression in the medial prefrontal cortex predicts impulsive choice in rats. Cereb. Cortex 20, 1064-1070. doi: 10.1093/cercor/bhp167

Ludvig, E. A., Balci, F., and Spetch, M. L. (2011). Reward magnitude and timing in pigeons. Behav. Processes 86, 359-363. doi: 10.1016/j.beproc.2011.01.003

Mahieux, F., Fénelon, G., Flahault, A., Manifacier, M. J., Michelet, D., and Boller, F. (1998). Neuropsychological prediction of dementia in Parkinson's disease. J. Neurol. Neurosurg. Psychiatry 64, 178-183. doi: 10.1136/jnnp.64.2.178

Malapani, C., Deweer, B., and Gibbon, J. (2002). Separating storage from retrieval dysfunction of temporal memory in Parkinson's disease. J. Cogn. Neurosci. 14, 311-322. doi: 10.1162/089892902317236920

Malapani, C., Rakitin, B., Levy, R., Meck, W. H., Deweer, B., Dubois, B., et al. (1998). Coupled temporal memories in Parkinson's disease: a dopamine-related dysfunction. J. Cogn. Neurosci. 10, 316-331. doi: 10.1162/089892998562762

Maricq, A. V., and Church, R. M. (1983). The differential effects of haloperidol and methamphetamine on time estimation in the rat. Psychopharmacology 79, 10-15. doi: 10.1007/BF00433008

Matell, M. S., Meck, W. H., and Nicolelis, M. A. L. (2003). Interval timing and the encoding of signal duration by ensembles of cortical and striatal neurons. Behav. Neurosci. 117, 760-773. doi: 10.1037/0735-7044.117.4.760

McCormick, D. A., Steinmetz, J. E., and Thompson, R. F. (1985). Lesions of the inferior olivary complex cause extinction of the classically conditioned eyeblink response. Brain Res. 359, 120-130. doi: 10.1016/0006-8993(85)91419-2

Meck, W. H. (2006). Neuroanatomical localization of an internal clock: a functional link between mesolimbic, nigrostriatal, and mesocortical dopaminergic systems. Brain Res. 1109, 93-107. doi: 10.1016/j.brainres.2006.06.031

Meck, W. H., and Church, R. M. (1987). Cholinergic modulation of the content of temporal memory. Behav. Neurosci. 101, 457-464. doi: 10.1037/07357044.101.4.457

Meck, W. H., Penney, T. B., and Pouthas, V. (2008). Cortico-striatal representation of time in animals and humans. Curr. Opin. Neurobiol. 18, 145-152. doi: 10.1016/j.conb.2008.08.002

Mehanna, R., and Jankovic, J. (2013). Movement disorders in cerebrovascular disease. Lancet Neurol. 12, 597-608. doi: 10.1016/S1474-4422(13)70057-7

Merchant, H., Harrington, D. L., and Meck, W. H. (2013). Neural basis of the perception and estimation of time. Annu. Rev. Neurosci. 36, 313-336. doi: 10.1146/annurev-neuro-062012-170349

Merchant, H., Luciana, M., Hooper, C., Majestic, S., and Tuite, P. (2008). Interval timing and Parkinson's disease: heterogeneity in temporal performance. Exp. Brain Res. 184, 233-248. doi: 10.1007/s00221-007-1097-7

Miller, E. K., and Cohen, J. D. (2001). An integrative theory of prefrontal cortex function. Annu. Rev. Neurosci. 24, 167-202. doi: 10.1146/annurev.neuro.24.1.167 Mirabella, G., Iaconelli, S., Modugno, N., Giannini, G., Lena, F., and Cantore, G. (2013). Stimulation of subthalamic nuclei restores a near normal planning strategy in Parkinson's patients. PLoS ONE 8:e62793. doi: 10.1371/journal.pone.0062793

Mita, A., Mushiake, H., Shima, K., Matsuzaka, Y., and Tanji, J. (2009). Interval time coding by neurons in the presupplementary and supplementary motor areas. Nat. Neurosci. 12, 502-507. doi: 10.1038/nn.2272

Morrison, C. E., Borod, J. C., Brin, M. F., Hälbig, T. D., and Olanow, C. W. (2004). Effects of levodopa on cognitive functioning in moderate-to-severe Parkinson's disease (MSPD). J. Neural Transm. 111, 1333-1341. doi: 10.1007/s00702-0040145-8

Narayanan, N. S., Land, B. B., Solder, J. E., Deisseroth, K., and Dileone, R. J. (2012). Prefrontal D1 dopamine signaling is required for temporal control. Proc. Natl. Acad. Sci. U.S.A. doi: 10.1073/pnas.1211258109

Narayanan, N. S., and Laubach, M. (2006). Top-down control of motor cortex ensembles by dorsomedial prefrontal cortex. Neuron 52, 921-931. doi: 10.1016/j.neuron.2006.10.021

Narayanan, N. S., and Laubach, M. (2009). Delay activity in rodent frontal cortex during a simple reaction time task. J. Neurophysiol. 101, 2859-2871. doi: 10.1152/jn. 90615.2008 
Niki, H., and Watanabe, M. (1979). Prefrontal and cingulate unit activity during timing behavior in the monkey. Brain Res. 171, 213-224. doi: 10.1016/00068993(79)90328-7

Norman, T., and Shallice, D. (1986). "Attention to action: willed and automatic control of behavior," in Consciousness and Self-Regulation: Advances in Research and Theory, eds R. J. Davidson, G. E. Shwartz, and D. Shapiro (New York: Plenum), $1-18$.

O’Boyle, D. J., Freeman, J. S., and Cody, F. W. (1996). The accuracy and precision of timing of self-paced, repetitive movements in subjects with Parkinson's disease. Brain 119(Pt 1), 51-70. doi: 10.1093/brain/119.1.51

Ogden, R. S., Salominaite, E., Jones, L. A., Fisk, J. E., and Montgomery, C. (2011). The role of executive functions in human prospective interval timing. Acta Psychol. (Amst.) 137, 352-358. doi: 10.1016/j.actpsy.2011.04.004

Olton, D. S., Wenk, G. L., Church, R. M., and Meck, W. H. (1988). Attention and the frontal cortex as examined by simultaneous temporal processing. Neuropsychologia 26, 307-318. doi: 10.1016/0028-3932(88)90083-8

Pascual-Sedano, B., Kulisevsky, J., Barbanoj, M., García-Sánchez, C., Campolongo, A., Gironell, A., et al. (2008). Levodopa and executive performance in Parkinson's disease: a randomized study. J. Int. Neuropsychol. Soc. 14, 832-841. doi: $10.1017 /$ S1355617708081010

Pastor, M. A., Artieda, J., Jahanshahi, M., and Obeso, J. A. (1992). Time estimation and reproduction is abnormal in Parkinson's disease. Brain 115(Pt 1), 211-225. doi: 10.1093/brain/115.1.211

Perbal, S., Deweer, B., Pillon, B., Vidailhet, M., Dubois, B., and Pouthas, V. (2005). Effects of internal clock and memory disorders on duration reproductions and duration productions in patients with Parkinson's disease. Brain Cogn. 58, 35-48. doi: 10.1016/j.bandc.2005.02.003

Phillips, A. G., Ahn, S., and Floresco, S. B. (2004). Magnitude of dopamine release in medial prefrontal cortex predicts accuracy of memory on a delayed response task. J. Neurosci. 24, 547-553. doi: 10.1523/JNEUROSCI.4653-03. 2004

Picton, T. W., Stuss, D. T., Alexander, M. P., Shallice, T., Binns, M. A., and Gillingham, S. (2006). Effects of focal frontal lesions on response inhibition. Cereb. Cortex 17, 826-838. doi: 10.1093/cercor/bhk031

Poewe, W., Wolters, E., Emre, M., Onofrj, M., Hsu, C., Tekin, S., et al. (2006). Long-term benefits of rivastigmine in dementia associated with Parkinson's disease: an active treatment extension study. Mov. Disord. 21, 456-461. doi: $10.1002 / \mathrm{mds} .20700$

Praamstra, P., and Pope, P. (2007). Slow brain potential and oscillatory EEG manifestations of impaired temporal preparation in Parkinson's disease. J. Neurophysiol. 98, 2848-2857. doi: 10.1152/jn.00224.2007

Rakshi, J. S., Uema, T., Ito, K., Bailey, D. L., Morrish, P. K., Ashburner, J., et al. (1999). Frontal, midbrain and striatal dopaminergic function in early and advanced Parkinson's disease A 3D [(18)F]dopa-PET study. Brain 122(Pt 9), 1637-1650. doi: 10.1093/brain/122.9.1637

Rattat, A. C. (2010). Bidirectional interference between timing and concurrent memory processing in children. J. Exp. Child Psychol. 106, 145-162. doi: 10.1016/j.jecp.2010.02.001

Riesen, J. M., and Schnider, A. (2001). Time estimation in Parkinson's disease: normal long duration estimation despite impaired short duration discrimination. J. Neurol. 248, 27-35. doi: 10.1007/s004150170266

Santangelo, G., Trojano, L., Vitale, C., Ianniciello, M., Amboni, M., Grossi, D., et al. (2007). A neuropsychological longitudinal study in Parkinson's patients with and without hallucinations. Mov. Disord. 22, 2418-2425. doi: 10.1002/mds. 21746

Sawada, Y., Nishio, Y., Suzuki, K., Hirayama, K., Takeda, A., Hosokai, Y., et al. (2012). Attentional set-shifting deficit in Parkinson's disease is associated with prefrontal dysfunction: an FDG-PET study. PLoS ONE 7:e38498. doi: 10.1371/journal.pone.0038498

Scatton, B., Javoy-Agid, F., Rouquier, L., Dubois, B., and Agid, Y. (1983). Reduction of cortical dopamine, noradrenaline, serotonin and their metabolites in Parkinson's disease. Brain Res. 275, 321-328. doi: 10.1016/0006-8993(83) 90993-9

Schneider, B. A., and Ghose, G. M. (2012). Temporal production signals in parietal cortex. PLoS Biol. 10:e1001413. doi: 10.1371/journal.pbio.1001413

Seamans, J. K., Floresco, S. B., and Phillips, A. G. (1998). D1 receptor modulation of hippocampal-prefrontal cortical circuits integrating spatial memory with executive functions in the rat. J. Neurosci. 18, 1613-1621.
Seamans, J. K., and Yang, C. R. (2004). The principal features and mechanisms of dopamine modulation in the prefrontal cortex. Prog. Neurobiol. 74, 1-58. doi: 10.1016/j.pneurobio.2004.05.006

Sheth, S. A., Mian, M. K., Patel, S. R., Asaad, W. F., Williams, Z. M., Dougherty, D. D., et al. (2012). Human dorsal anterior cingulate cortex neurons mediate ongoing behavioural adaptation. Nature 488, 218-221. doi: 10.1038/nature11239

Shimamura, A. P., Janowsky, J. S., and Squire, L. R. (1990). Memory for the temporal order of events in patients with frontal lobe lesions and amnesic patients. Neuropsychologia 28, 803-813. doi: 10.1016/0028-3932(90)90004-8

Simen, P., Balci, F., de Souza, L., Cohen, J. D., and Holmes, P. (2011). A model of interval timing by neural integration. J. Neurosci. 31, 9238-9253. doi: 10.1523/JNEUROSCI.3121-10.2011

Sternberg, D. A., Ballard, K., Hardy, J. L., Katz, B., Doraiswamy, P. M., and Scanlon, M. (2013). The largest human cognitive performance dataset reveals insights into the effects of lifestyle factors and aging. Front. Hum. Neurosci. 7:292. doi: 10.3389/fnhum.2013.00292

Stuss, D. T., Alexander, M. P., Shallice, T., Picton, T. W., Binns, M. A., Macdonald, R., etal. (2005). Multiple frontal systems controlling response speed. Neuropsychologia 43, 396-417. doi: 10.1016/j.neuropsychologia.2004. 06.010

Takahashi, H., Yamada, M., and Suhara, T. (2012). Functional significance of central D1 receptors in cognition: beyond working memory. J. Cereb. Blood Flow Metab. 32, 1248-1258. doi: 10.1038/jcbfm.2011.194

Taylor, K. M., Horvitz, J. C., and Balsam, P. D. (2007). Amphetamine affects the start of responding in the peak interval timing task. Behav. Processes 74, 168-175. doi: 10.1016/j.beproc.2006.11.005

Torta, D. M. E., Castelli, L., Latini-Corazzini, L., Banche, A., Lopiano, L., and Geminiani, G. (2010). Dissociation between time reproduction of actions and of intervals in patients with Parkinson's disease. J. Neurol. 257, 1356-1361. doi: 10.1007/s00415-010-5532-5

Uc, E. Y., Rizzo, M., Anderson, S. W., Qian, S., Rodnitzky, R. L., and Dawson, J. D. (2005). Visual dysfunction in Parkinson disease without dementia. Neurology 65, 1907-1913. doi: 10.1212/01.wnl.0000191565.11065.11

Van Spaendonck, K. P., Berger, H. J., Horstink, M. W., Buytenhuijs, E. L., and Cools, A. R. (1996). Executive functions and disease characteristics in Parkinson's disease. Neuropsychologia 34, 617-626. doi: 10.1016/0028-3932(95) 00159-X

Wang, M., Vijayraghavan, S., and Goldman-Rakic, P. S. (2004). Selective D2 receptor actions on the functional circuitry of working memory. Science 303, 853-856. doi: $10.1126 /$ science. 1091162

Whitehouse, P. J., Hedreen, J. C., White, C. L., and Price, D. L. (1983). Basal forebrain neurons in the dementia of Parkinson disease. Ann. Neurol. 13, 243-248. doi: 10.1002/ana.410130304

Wild-Wall, N., Willemssen, R., Falkenstein, M., and Beste, C. (2008). Time estimation in healthy ageing and neurodegenerative basal ganglia disorders. Neurosci. Lett. 442, 34-38. doi: 10.1016/j.neulet.2008.06.069

Williams, G. V., and Goldman-Rakic, P. S. (1995). Modulation of memory fields by dopamine D1 receptors in prefrontal cortex. Nature 376, 572-575. doi: $10.1038 / 376572 \mathrm{a} 0$

Williams, S. M., and Goldman-Rakic, P. S. (1998). Widespread origin of the primate mesofrontal dopamine system. Cereb. Cortex 8, 321-345. doi: $10.1093 /$ cercor/8.4.321

Williams-Gray, C. H., Evans, J. R., Goris, A., Foltynie, T., Ban, M., Robbins, T. W., etal. (2009). The distinct cognitive syndromes of Parkinson's disease: 5 year follow-up of the CamPaIGN cohort. Brain 132, 2958-2969. doi: 10.1093/brain/awp245

Williams-Gray, C. H., Foltynie, T., Brayne, C. E. G., Robbins, T. W., and Barker, R. A. (2007). Evolution of cognitive dysfunction in an incident Parkinson's disease cohort. Brain 130, 1787-1798. doi: 10.1093/brain/ awm 111

Wylie, S. A., Ridderinkhof, K. R., Elias, W. J., Frysinger, R. C., Bashore, T. R., Downs, K. E., et al. (2010). Subthalamic nucleus stimulation influences expression and suppression of impulsive behaviour in Parkinson's disease. Brain 133, 3611-3624. doi: 10.1093/brain/awq239

Wylie, S. A., van den Wildenberg, W., Ridderinkhof, K. R., Claassen, D. O., Wooten, G. F., and Manning, C. A. (2012). Differential susceptibility to motor impulsivity among functional subtypes of Parkinson's disease. J. Neurol. Neurosurg. Psychiatry 83, 1149-1154. doi: 10.1136/jnnp-2012-303056 
Zesiewicz, T. A., Sullivan, K. L., Arnulf, I., Chaudhuri, K. R., Morgan, J. C., Gronseth, G. S., et al. (2010). Practice parameter: treatment of nonmotor symptoms of Parkinson disease: report of the Quality Standards Subcommittee of the American Academy of Neurology. Neurology 74, 924-931. doi: 10.1212/WNL.0b013e3181 d55f24

Zetterström, T., Sharp, T., Marsden, C. A., and Ungerstedt, U. (1983). In vivo measurement of dopamine and its metabolites by intracerebral dialysis: changes after d-amphetamine. J. Neurochem. 41, 1769-1773. doi: 10.1111/j.14714159.1983.tb00893.x

Conflict of Interest Statement: The authors declare that the research was conducted in the absence of any commercial or financial relationships that could be construed as a potential conflict of interest.
Received: 30 July 2013; accepted: 14 October 2013; published online: 31 October 2013.

Citation: Parker KL, Lamichhane D, Caetano MS and Narayanan NS (2013) Executive dysfunction in Parkinson's disease and timing deficits. Front. Integr. Neurosci. 7:75. doi: 10.3389/fnint.2013.00075

This article was submitted to the journal Frontiers in Integrative Neuroscience. Copyright (c) 2013 Parker, Lamichhane, Caetano and Narayanan. This is an openaccess article distributed under the terms of the Creative Commons Attribution License (CC BY). The use, distribution or reproduction in other forums is permitted, provided the original author(s) or licensor are credited and that the original publication in this journal is cited, in accordance with accepted academic practice. No use, distribution or reproduction is permitted which does not comply with these terms. 